\title{
Theorizing participation in health promotion: A literature review
}

\author{
Benjamin Marent*, Rudolf Forster and Peter Nowak \\ *School of Applied Social Science, University of Brighton \\ b.marent@brighton.ac.uk
}

Published in: Social Theory \& Health (2012) 10, 188-207. doi:10.1057/sth.2012.2;

published online 22 February 2012

http://www.palgrave-journals.com/sth/journal/v10/n2/abs/sth20122a.html

\begin{abstract}
Participation is a key principle in health promotion. Numerous methods and tools are available and several models are used to guide and evaluate participatory endeavours in the health field. Recently, however, the lack of conceptual clarity and the normative underpinning of participation have been criticized and more substantiation by social theories has been suggested. To identify theoretical approaches applied to the topic so far and elaborate their potential contribution, a systematic literature review was conducted. Very few papers were identified that included substantial use of social theories. Their main arguments were grouped and critically discussed within a framework of three key questions. The first analyses the functions of participation and expands either the 'democratic' or 'utilitarian' perspective commonly suggested. The second asks how lay actors can be constituted as interested and competent stakeholders within their socio-political environments. The third complements an actor-focused perspective by elaborating participatory processes as asymmetric and conflictual. We conclude that the theoretical contributions available offer relevant stimulation for the conceptualization and implementation of participation in health promotion. Future theoretical work could benefit from cross-fertilization with theoretical debates in other areas of health promotion and from more explicitly elaborating the social context within which participation takes place.
\end{abstract}

Keywords health promotion; participation; lay participation; decision-making; social theory

\section{Introduction}

Participation has been a World Health Organization strategy since the Alma Ata Declaration (WHO, 1978). In health issues, participation has been encouraged from two distinct perspectives: first, as a democratic ideal reflecting the underlying values of equal representation and social justice; and second, as a means to an end, supporting the effectiveness of health programmes (Morgan, 2001; Wait and Nolte, 2006).

The Ottawa Charter (WHO, 1986) stressed the necessity for participation, particularly for health promotion and outlined it as a key guiding principle (Rootman et al, 2001). The basic assumption in health promotion is that people cannot fully realise their health potential if they do not have control over the (internal and external) factors that determine health (Wallerstein, 1992). Therefore, it is regarded as essential that 'lay'-people (indicated by various terms such as 'public', 'citizens', 'communities' and 'users') participate in the development and implementation of health promotion policies and programmes. Moreover, such participation is regarded as important to identify health issues that matter to the people concerned and to generate programmes that take their values and practices into account.

Reviews on participation in health care and health promotion (Labonte, 1997; Zakus and Lysack, 1998; Rifkin et al, 2000; White, 2000; Morgan, 2001; Rifkin, 2009; Preston et al, 2010) conclude that conceptual clarity is lacking, outcomes are difficult to assess and there are numerous practical problems. 
The wide-ranging understanding of 'participation' is reflected in the vast number of methods and tools elaborated in health promotion and health care to translate the principle of participation into practice. Participatory approaches take such diverse forms as advisory councils, working groups, open space, focus groups, juries, rapid assessments, opinion polls, surveys and so on (for example, Rifkin and Pridmore, 2001; Cornwall, 2011).

To differentiate and evaluate various participatory methods several models have been developed that suggest that participation should be understood as a continuum of more or less power. The classic attempt in this direction was Arnstein's (1969) 'ladder of citizen participation'. In health promotion, many approaches lean towards this metaphor, while renaming, adding or eliminating some of its rungs (for example, Hart, 1992). The ladder metaphor has been criticized because it limits the potential for sharing knowledge and experiences between experts and lay people (Tritter and McCallum, 2006).

The underlying concepts of participation are criticized for being normative (by considering participation as a value in itself) and for assuming the intrinsic desirability of (a high level of) participation (Contandriopoulos, 2004; Potvin, 2007). Thereby, the communicative aspects and embedding in social situations have not been adequately understood. Contandriopoulos as well as Potvin use certain schools of social theory to reflect the complexity and main challenges of participation.

When approaching a complex phenomenon, one cannot simultaneously be general, accurate and simple (Weick, 1979). Methods, models and social theories offer different ways of approaching the complexity of participation. Participatory methods combine accuracy and simplicity by providing practitioners with detailed guidelines to implement a particular method within a specific context. By building on virtues of accuracy and simplicity, however, such methods sacrifice generality. Models offer generality and simplicity through simple premises. However, these premises are not accurate for a detailed understanding of the concrete situation or of the complex social processes involved. Social theories could offer devices to capture the general social processes at play when participation is implemented and then accurately analyse these processes in various dimensions and by embedding them in broader social structures. However, social theory sacrifices the simplicity needed for practical application.

Thus, methods, models and social theories offer different opportunities and entail specific constraints. A comprehensive research discourse would pursue all three approaches and provide opportunities for trade-offs (Weick, 1979).

Up to now methods and models have dominated the health promotion discussion. By contrast, little effort has been made to systematically connect these approaches to social theory. Through a systematic literature review, this article aims to identify theoretical papers referring to participation in health promotion and to elaborate their main ideas and arguments. It will be identified which problems of participation in health promotion programmes are addressed using social theory and which theoretical approaches are suggested for their better understanding. This article intends, thereby, to stimulate further social theoretical debates on participation in health promotion and to elaborate the potential contribution of theory in developing models and methods.

\section{Method}

\section{Database searches}

On the basis of our analysis of previous review articles (mostly published up to 2000) we developed a comprehensive search strategy to identify more recent publications. We searched seven databases (search date: April 2009) from 2000 to April 2009: Scopus, WEB of Science, Applied Social Sciences 
Index and Abstracts, Social Science Index, Psyclnfo, PubMed and Embase. We chose the following search terms to allow a broad search: [health promotion OR health promoting] AND [participation OR involvement $O R$ consultation $O R$ engagement] AND [theor*OR model*OR framework*OR pathway*OR approach*]. The search was limited to journal articles written in English or German.

\section{Inclusion criteria}

We selected articles that met the following criteria:

(i) Articles must examine theoretical concepts to observe, analyse and/or guide participation in development and implementation of health promotion policies and programmes (not only referring to people taking part in pre-designed health promotion programmes).

(ii) The theoretical concepts used must explicitly refer to social theories (here defined as: theoretical frameworks used to study and interpret social phenomena within a particular school of thought).

\section{Selection method}

The literature search resulted in a total of 2228 citations (Figure 1). Titles and abstracts of the citations were independently assessed (against the inclusion criteria) by two researchers and 168 full manuscripts were retrieved for citation because they presumably met the inclusion criteria or abstract information was insufficient to make a judgement. Full texts were again assessed independently by two authors. Discrepancies within the assessment process were noted and resolved by consensus after discussion within the research team. Full text screening led to the exclusion of 160 citations: 148 did not focus on our research questions (inclusion criteria (i)). Twelve papers highlighted conceptual devices on participation, but without reference to a theoretical school or perspective (inclusion criteria (ii)). One additional (book-)article (Potvin, 2007) known to the research team was also included. In addition, we checked the reference lists of the nine remaining articles and included two additional papers (Campbell and Jovchelovitch, 2000; Contandriopoulos, 2004). For 11 publications, data extractions were made and double-checked by two authors. Four papers had some shortcomings and were not included in the further process of analysis: Abelson et al (2003) and Morris (2003) used theoretical distinctions, but did not elaborate a detailed theoretical approach. Cornish (2006) focused on pragmatist theory to understand participation, but did not ground further reasoning on specific theoretical concepts. Dutta and Basnyat (2008) elaborated theoretical aspects of participatory communication, but neither referred to specific theoretical concepts nor explicitly suggested an approach of their own. Seven articles were included in the final analysis (Figure 1). 


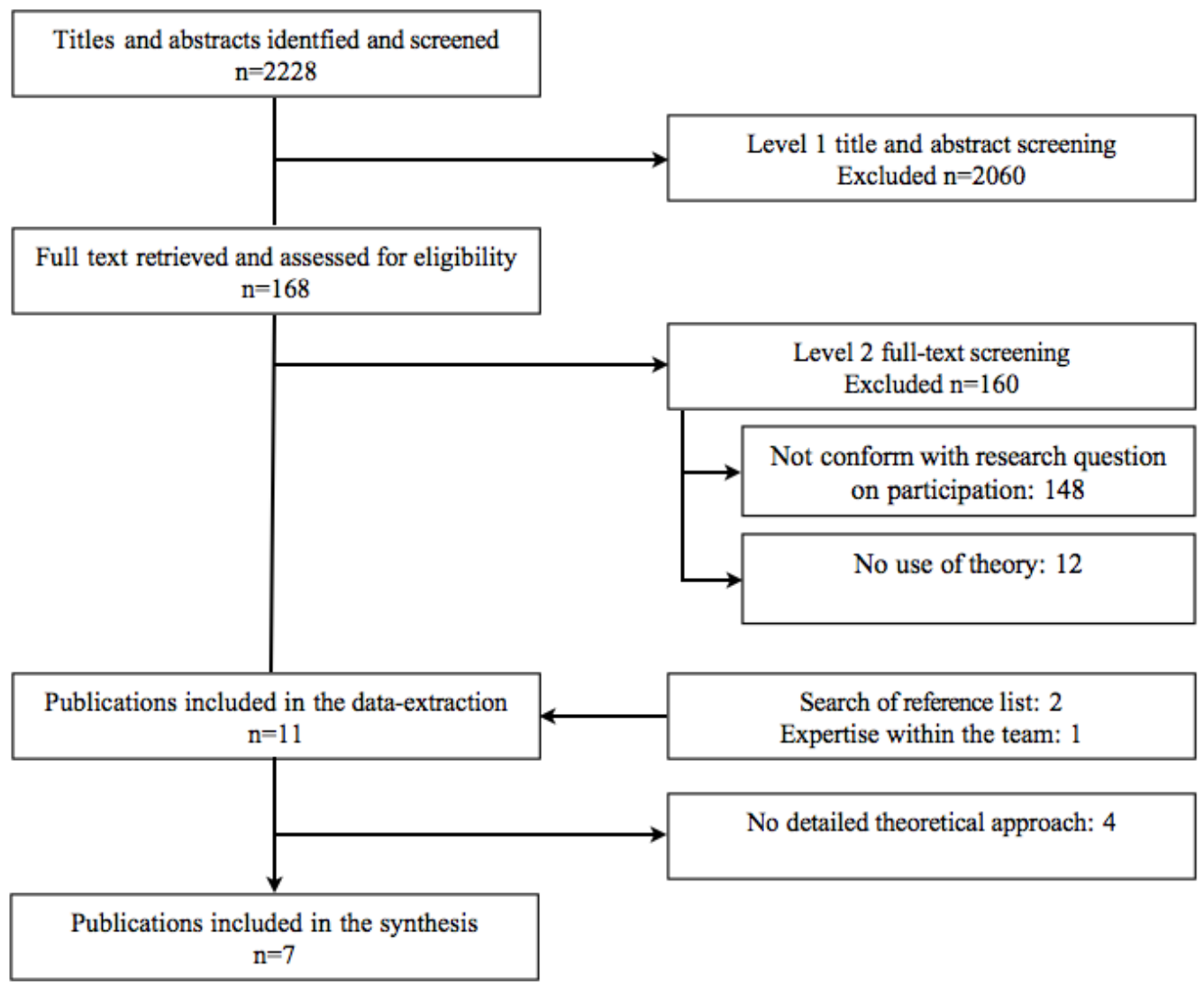

Figure 1: Flow diagram of study selection process

\section{Analysis}

The process of analysis was inspired by well-known methodologies for the synthesis of qualitative research (Noblit and Hare, 1988; Paterson et al, 2001). The interpretative aim of Noblit and Hare (1988) is the translation of ideas, concepts and metaphors across different qualitative studies. Paterson et al (2001) underline the importance of synthesizing theoretical constructs. We did not attempt to develop a 'meta-theory' of participation in health promotion, but to present an integrated picture of the main theoretical discussions.

We started the analysis by becoming familiar with the material, reading and rereading the papers included. In a second step, each author independently identified key questions of participation that each article builds upon as a starting point for its respective analysis. As a result of several group discussions we integrated the theoretical approaches identified into three key questions. In a final step, we discussed these results and their implications for future theoretical development and debate in health promotion.

\section{Results}

Seven articles, which make substantial use of social theory to elaborate on participation in health promotion, were identified (Table 1). These articles draw on seven different social theories: critical theory (Habermas, 1984), critical pedagogy (Freire, 1970), post-structuralism (Foucault taken up by Petersen and Lupton, 1997), theory of practice (Bourdieu, 1984), theory of citizen deliberation (Taylor, 1985), theory of modernity (Beck et al, 1994) and actor-network- theory (Callon, 2001). The citations refer only to the main source used in the included articles. 
The result of the analysis process is presented around three key questions. These seem to be broad enough to outline common issues and specific enough to accurately grasp their main arguments. The first key question discusses the function of participation within the societal context in which health promotion takes place. The second addresses the problem that lay actors are not usually established as 'stakeholders' in health promotion and asks how they might be constituted as actors. The third concerns the complexity of participatory processes and problems with their initiation and organization.

The following sections will describe the various theoretical perspectives suggested. A more detached, integrated and critical picture is the focus of the discussion.

\begin{tabular}{|c|c|c|c|}
\hline Article & Theoretical school & Representatives & Specific theoretical approach \\
\hline \multirow[t]{2}{*}{ Baillie et al (2000) } & Critical theory & Habermas & $\begin{array}{l}\text { Differentiation of knowledge- } \\
\text { constitutive-interests }\end{array}$ \\
\hline & Critical theory & Habermas & Communicative action \\
\hline $\begin{array}{l}\text { Campbell and } \\
\text { Jovchelovitch (2000) }\end{array}$ & Critical pedagogy & Freire & Critical consciousness \\
\hline \multirow{3}{*}{$\begin{array}{l}\text { Ramella and de la Cruz } \\
\text { (2000) }\end{array}$} & Poststructuralism & Peterson/ Lupton & Power relations \\
\hline & Critical pedagogy & Freire & Critical consciousness \\
\hline & Critical theory & Habermas & Communicative action \\
\hline $\begin{array}{l}\text { Contandriopoulos } \\
(2004)\end{array}$ & Social theory & Bourdieu & $\begin{array}{ll}\text { Symbolic } & \text { struggle; } \\
\text { objectification } & \end{array}$ \\
\hline Murphy (2005) & $\begin{array}{l}\text { Political philosophy; } \\
\text { theory of citizen } \\
\text { deliberation }\end{array}$ & Taylor & $\begin{array}{l}\text { Expansion of consciousness; } \\
\text { deliberation }\end{array}$ \\
\hline \multirow[t]{2}{*}{ Potvin (2007) } & Critique of modernity & $\begin{array}{l}\text { Beck/ Giddens/ } \\
\text { Lash }\end{array}$ & Reflexivity; individualization \\
\hline & Actor-network-theory & Callon & $\begin{array}{l}\text { Socio-technical networks; } \\
\text { translation }\end{array}$ \\
\hline Stephens (2007) & Social theory & Bourdieu & Social identity \\
\hline
\end{tabular}

Table 1: Description of the articles included in this review

\section{Key question 1: What is the function of participation in health promotion?}

Three articles dealing with this question argue that by using social theory, the normative and ideological grounding of participation in health promotion can be better reflected and possibly overcome. Using different approaches, the function of participation is discussed, asking why a) it has become a strategy to address changing health problems; $b$ ) it is a means to identify community values; c) it contributes to expanding established power relations.

\section{a) Participation as a strategy to address changing health problems and challenges}

For Potvin (2007), the use of social theory is a means to reframe participation as professional practice rather than ideology. Drawing on the theory of modernity outlined by Beck et al (1994), Potvin stresses the challenges arising for health promotion from societal transformation. Two key elements 
of the theory of modernity are taken up. "Reflexivity" indicates that as scientifically based knowledge is introduced into the social world through media, education or professional practice, it alters social structure and practices at the same time. Thus, knowledge production in modernity does not lead to increased controllability but rather contributes to social change and complexity. "Individualization" highlights the fact that individuals increasingly become the main decision-makers for their own lifecourses. The individual biography is no longer standardized through traditional patterns, but to a great extent is a "do-it-yourself biography" (Beck, cited by Potvin, 2007, p. 106).

As a result of reflexivity and individualization, modern society is characterized by uncertainty. Along with changing knowledge, attitudes and behaviour, health problems and challenges are also changing constantly. According to Potvin, health promotion faces not only the challenge of meeting different health problems, but also of ensuring that its programs effectively relate to the knowledge, attitudes and behaviour of the people concerned. Under these circumstances, health promotion programmes cannot rely solely on expert knowledge and prefixed top-down solutions. Rather, participation should be seen as a strategy to acknowledge the dynamics of modern society. Through participation, diverse local actors become involved and horizontal relationships may be established for approaching health problems, local resources and possible solutions from various perspectives. Thus it might ensure that health promotion actions address relevant health issues in a way that is accessible and understandable for people in different life circumstances. But participation is not only a strategy to deal adequately with uncertainty, but also in itself a source of uncertainty as the outcome is always open.

\section{b) Participation as a means to identify and reconstruct community values}

Collective participation is based on the assumption that various actors can identify common concerns and act accordingly. Murphy (2005, p. 172) asks "how citizens may articulate and share values that could affect health promotion" by referring to Taylor's (1985) theory of citizen deliberation. Taylor asserts that while making a choice, a person is oriented towards values which are not primarily situated within the individual mind but "out there in the practices themselves" (Taylor, cited by Murphy, 2005, p. 175).

Community practices provide the context for a person's reasoning. Through experiences, what matters to the community consciousness is expanded. Through deliberation, people are concerned with their multiple intentions and thereby make "strong evaluations" of their values (Murphy, 2005). Thus people's choices become not solely outcome-orientated but also lean towards core questions about the kind of community they aspire to be and may transcend self-interests by identifying common values.

Murphy points to different UK studies to substantiate her theoretical perspective. These studies showed that citizens polled through short individual interviews are more likely to opt for health priorities that reflect individual interests and reproduce prejudices. By contrast, through focus groups that meet over time, citizens become more prepared to share broad community health perspectives. Murphy concludes that if citizens are supported with appropriate forums and given time to evaluate their values, they can expand their consciousness and become more sensitive to the health experiences of vulnerable community members.

\section{c) Participation as a governance technique}

Ramella and de la Cruz (2000) introduced the post-structuralist perspective (referring to Peterson and Lupton, 1996) as an opportunity to reflect critically on participatory health promotion. Based on a discursive conception of power, they assume the constant reproduction of power within knowledge and practices of participatory processes. The post-structuralist perspective points to a "neo-liberal democratic discourse" (Ramella and de la Cruz, 2000, p. 274) incorporated into claims for 
participation. Leadership is transformed from hierarchical exclusion towards a governance technique that secures legitimacy, but also its influence, through expanding participatory inclusion spaces. In these spaces, experts control the techniques and scope of engagement while lay people are prompted to self-discipline. Moreover, participation may reproduce existing power relations if experts and citizens enjoying a higher social status use it to legitimate their point of view. People with lower social status often lack the communicative skills to voice their opinions and may be influenced by reasonable sounding arguments of others.

While Ramella and de la Cruz acknowledge the critical stance of post-structuralism, they criticize its lack of consideration for how health promotion might overcome or at least narrow problems of power and domination and facilitate spaces where participants could effectively exchange views and work together. They suggest making use of Habermas' theoretical concepts as a remedy for this dilemma (cf. key question 3 ).

\section{Key question 2: How are lay actors constituted as participants in health promotion?}

Models that advocate collective participation often take lay people's motivation, availability and competence for granted. Yet, problems arise if lay actors lack motivation, resources or the ability to take part or if professionals are ambiguous about why they should engage with them. The social theories highlighted in this section address these problems by elaborating a) the relevance of lay knowledge and experience, b) the possibility of empowering people through dialogue and c) the relevance of identification with a particular programme.

\section{a) Lay agency as authentic experience}

Baillie et al (2000) try to explain the limited success of many health promotion initiatives by using Habermas' critical theory (1984). They take up Habermas' differentiation of three major "interests" to gain knowledge about the world. The "empirical interest" refers to efforts of actors to predict and control their environments, exemplified by the scientific paradigm whereby phenomena are objectified, observed and managed. The "practical interest" secures and expands possibilities of mutual and self-understanding in a way that fits best under given circumstances. The interpretive paradigm of hermeneutics exemplifies this interest as it tries to understand the world from subjective perspectives. However, this approach uncritically accepts the way things are (Baillie et al, 2000). "Emancipatory interest" also acknowledges the unique experiences and knowledge of people within their different life-worlds. However, it concludes that it is not possible to know and control their interests or needs. Emancipatory interest is seen as a theoretical device to critically question dogmatism and domination.

Baillie et al (2000) assume that health promotion has been mainly guided by empirical and practical interests. Programme development has not strongly pursued an emancipatory interest by enabling lay people ("authentic speakers") to raise their voices and challenge professionals ("authoritative speakers"). From a Habermasian perspective people hold a unique position with diverse experiences, knowledge and needs embedded in their life worlds. This is the backdrop from which people approach health promotion programmes and use them as a meaningful resource. Baillie et al portray emancipatory health promotion as an alternative, building on lay people's knowledge and experiences to address health issues within their local context.

\section{b) Lay agency as critical consciousness}

Two papers (Campbell and Jovchelovitch, 2000; Ramella and de la Cruz, 2000) draw on the critical pedagogy of Freire (1970) to argue that participatory dialogue between health professional and lay people is a pre-condition for successful health promotion. 
According to Freire, teaching is not a transfer of knowledge, but the creation of the "possibilities for the production and construction of knowledge" (Ramella and de la Cruz, 2000, p. 277). Teaching implies the generation of spaces for people to express and discuss their life experiences in order to establish a relationship with their socio-political environment.

From this perspective, participation generates spaces for joint action between actors having different forms of knowledge. By discussing their issues and concerns within the arena of their everyday lives, people may acquire skills to voice their opinions and relate their problems to their socio-political environment. Establishing this connection between one's situation and the broader environment means developing "critical consciousness", which enhances people's potential to take action for change in community affairs.

Ramella and de la Cruz illustrate their approach with a sexual health promotion project in Peru. Extremely deprived adolescents were enabled to present and discuss their experiences and to critically reflect issues of their sexual health by producing stories recorded with audio-visual equipment.

\section{c) Lay agency as complex social identity}

Even if health promoters create spaces for people to share experiences and offer possibilities for the development of adequate initiatives, they may fail to reach the people concerned. According to Stephens (2007) and Campbell and Jovchelovitch (2000), this may happen because participatory initiatives do not adequately consider the complexity of social identities involved.

Both papers conceptualize participation itself as an expression and practice of social identity. Building on Bourdieu's theory of practice, Stephens notes that identities are not fixed, but shifting and fragmented and may be understood "as embodied practices that are structured by habitus or social background, and also by differing social purposes across different fields of practice" (Stephens, 2007, p. 958). Accordingly, he points out that participation in designing and implementing health promotion programmes depends on people's ability to identify with them. Through a qualitative study conducted in a deprived city neighbourhood in New Zealand she found that, in many cases, people do not have the feeling that community health programmes are for them but rather for other groups. Stephens concludes that this is because these programmes located their efforts within "communities of place" people were not able to identify with. More appropriate, but also more demanding for health programmes is addressing "communities of identity". Therefore an understanding of different identity practices is important for designing health programmes with which the people concerned can identify and engage (Stephens, 2007; Campbell and Jovchelovitch, 2000).

\section{Key question 3: How can participatory processes be understood, initiated and organized?}

Participation as a complex social process brings together different actors building on and negotiating different kinds of knowledge and perspectives through different phases. This social practice may be more adequately understood through social theory. A better understanding of the social processes participation entails could contribute to initiating and organizing it in a way that facilitates its purported objectives.

The social theories highlighted in this section focus on the procedural character of participatory decision processes. These processes are understood differently through concepts such as a) mutual understanding of perspectives, b) translation of knowledge and interests and c) objectification of status. At the same time, each theory acknowledges that the outcome of such processes remains uncertain.

a) Participation as a process based on mutual understanding 
Establishing participatory health promotion may run the risk that available spaces are used strategically by powerful actors to impose their views upon others. Moreover, health promoters themselves may (consciously or not) strongly voice their perspectives, while the opinions of others remain unheard.

Baillie et al (2000) and Ramella and de la Cruz (2000) introduce Habermas' (1984) theory of communicative action as a device to distinguish strategic and systematically distorted communication from open communication. Communicative action, according to Habermas, is oriented towards mutual understanding and basic social action. Habermas identifies forms of social action that are directed towards domination as derivate forms. Habermas' theory offers some criteria to ensure the soundness of a communicative environment in which participants are enabled to discuss freely, share their opinions and seek mutual understanding.

According to Baillie et al (2000) who applied Habermas' theory when setting up a primary cancer prevention program, these criteria include: equality and mutual accountability which ensure that all participants have equal opportunity to initiate discussions. Deciding upon the appropriateness of content, methods and actions should involve all participants. Furthermore, participation implies a collaborative process based on negotiations. Those delivering programmes and those receiving them discuss and decide the programme's content together. It should be possible to continually challenge the legitimacy of knowledge through critique at every stage. The principle of action stresses the difference between "knowing better" and "doing better" as action "seeks to uncover and, if necessary, change the social constructions that inhibit or prevent positive health choices" (Baillie et al, 2000, p. 450).

\section{b) Participation as a multidirectional translation process}

Potvin (2007), building on Callon's (2001) actor-network-theory, considers health promotion programmes as "socio-technical networks" composed of "objectives, resources, knowledge, experts, lay people, staff members, and contextual elements all forming a composite of human and non-human actors" (Potvin, 2007, p. 113). Accordingly, health promotion is understood as a translation process in which " $(v)$ arious bodies of knowledge have to negotiate their role in the construction of problems that need to be addressed locally and in the elaboration of solutions" (Potvin, 2007, p. 114). Callon (2001) describes translation as an ensemble of four iterative operations leading to the creation of a network-the programme's social space.

Problematisation is the operation by which relevant actors for a given issue are identified and the meaning of the issues is expanded. Within the interest operation, the initiators of the process develop media and mediated actions in order to impose the other actor's role and identity. Here, the specific link between actors and issue is fixed and their relation to other actors is spelled out. Enrolment indicates the operation by which roles are defined, assigned and accepted. Thereby actors become part of the network and "their roles are coordinated in the pursuit of a common objective" (Potvin, 2007, p. 117). The fourth operation is called mobilization of actors. Not all actors composing a group are part of the entire translation process throughout its various operations; thus, groups of actors have to be represented and mobilized by spokespersons.

Understanding participation as a multidirectional translation, Potvin says, means that health promoters not only problematize a given issue and thus initiate and shape the translation process. Rather, they also call up different interest groups to act as translators and, thereby, to actively develop their own problematisation of an issue. Participatory health promotion connects different networks through spokespersons representing these networks. Analysing a school diabetes prevention project in Canada, Potvin illustrates how the actions of actors within their networks become observable and attributable through terms like problematisation, enrolment, interestment and mobilization. She demonstrates that each issue is observed differently from different positions and through different 
interests and its meaning is expanded. Participatory decision processes thus lead to an increased number of possible choices (alternatives) which may be translated into sustainable decisions. However, Potvin points to controversies between spokespersons and the people they represent, as well as between spokespersons representing different interests as essential parts of participatory processes.

\section{c) Participation as a symbolic struggle for representation and meanings}

According to Contandriopoulos (2004) "public participation" mostly lacks the strong formal representation usually achieved by elections. He uses social theory to reconstruct the process by which actors and their meanings gain legitimacy in public participation. Moreover, he corroborates his theoretical elaboration with three case studies representing different forms of public participation in Quebec's health care system.

Contandriopoulos draws on Bourdieu's concept of "symbolic struggle" for understanding processes of legitimation. "A symbolic struggle is a struggle for the imposition of meanings or perspectives [...] by which agents or institutions [...] try to impose their vision of the world as well as the categories they use to understand it, upon other agents" (Contandriopoulos, 2004, p. 332). Furthermore Bourdieu's concept of objectification is introduced to describe how the subjective perspectives of various actors could be transformed into perceived normality. It is suggested that social and political relations do not rest on an objective basis but are constantly reinvented through symbolic struggles and objectification.

In the case of public participation, representatives involved are either self-designated or appointed through weak formal procedures. Therefore, "they are forced to become more visibly and directly involved in symbolic struggles for the objectification of their representatives' status" (Contandriopoulos, 2004, p. 322). Accordingly, effective participation depends on the ability of representatives to appear as legitimate spokespersons. Objectification becomes the aim of symbolic struggles in two ways: first, to impose one's own perspective and second, to legitimate one's status as a representative.

\section{Discussion}

Social theories come up with different answers to and perspectives on key questions of participation. This review illustrates a multitude of perspectives emerging from different theoretical backgrounds. In the following, these different theoretical answers are critically discussed and related to each other.

Social theories elaborating the function of participation considerably broaden either the "democratic" or "utilitarian" perspective usually suggested in the literature. From their different points of departure, however, they develop quite different understandings of the rationale underlying participatory practice.

The post-structuralist perspective as introduced by Ramella and de la Cruz (2000) is a prominent strand within a critical sociological analysis of health promotion (Bunton et al, 1995). It aims more to critically reflect and deconstruct the contradictions and hidden agendas of health promotion than to contribute to its development. Post-structuralist critique deconstructs manipulative and tokenistic attempts at participatory health promotion by portraying it as a professional effort to govern lay people's attitudes and behaviours. However - unlike the "ladder model" - it does not assume that these could be overcome by offering lay people a higher "rung" of participation. Power is not understood as an entity that may be simply exchanged between 
professionals and lay people, but rather as hidden in dominant forms of knowledge, language and rhetoric which could be reproduced in all forms of participatory practice.

By contrast, the theory of reflexive modernity as introduced by Potvin (2007) provides health promoters with a theoretical reflection that frames participation as a strategy to better grasp the dynamics of on-going societal transformation. Theoretical reflection gains importance because empirical evidence of positive outcomes of participation is scarce and its value is uncritically taken for granted. Drawing on Taylor's theory, which locates citizen participation in the context of modern democracy and its crisis, Murphy (2005) also tries to transcend the normative rationale of participation. Participation could broaden perspectives and reorient programmes and practices of health promotion by facilitating the reflection of common values.

So, from the post-structuralist perspective the issue of instrumentalisation is inherent and insuperable in participatory practices as they are part of a constant transformation of power technologies which can better be critically questioned by "resistance" than by participation. This leaves health promoters rather perplexed, but is possibly an encouragement for critical social movements in health. By contrast, the theories of modernity and citizens' deliberation frame participation in a positive way, but only marginally point to its risks. Yet, a deeper theoretical understanding of the risks of participation is elaborated in the other two, partially intersecting strands of theoretical discussions identified: the way lay actors are constituted as agents in participatory processes and the way these processes take place and are organized.

The relevance of enabling lay actors to become "empowered" participants in health promotion as introduced in three articles (Baillie et al, 2000, Ramella and de la Cruz, 2000, Campbell and Jovchelovitch, 2000) draws on Habermas' concept of "emancipatory interest" and/or Freire's notion of "critical consciousness". We suggest that both theories have a common understanding of communicative arrangements. Communicative processes are not understood as simple transmission of information or meaning. Rather, information needs to be interpreted and its meaning is constructed from the backdrop of the receivers' knowledge and experiences. Based on that understanding, the three articles identified argue that efforts to change lifestyles and circumstances must be related to people's experiences and knowledge to ensure that programmes are seen as relevant resources. Health issues need to be actively discussed by people and related to their socio-political environment to have learning effects that may lead to social action. Authors building on Habermas' and Freire's theories agree that health promotion strategies should offer "open" spaces where lay people could autonomously identify and discuss their issues while professionals take, at best, a supporting role.

In our view Stephens (2007) and Campbell and Jovchelovitch (2000) also address a communicative challenge. Both raise the question of how lay actors could be motivated to engage actively in creating relevant initiatives in the first place. Health promotion, they state, often uses overly simple identity and community concepts to establish relationships with lay people. Their approaches underline that considering different identities is a prerequisite to motivating lay people to participate. While participatory health promotion is aligned towards a community setting in all papers discussed in this review, only these two articles theorize the different meanings of community.

Theories suggested for a better understanding of participatory processes complement an actor-focused perspective. Two quite different uses of theory were found: One uses social theory as a device to deduce principles for an ideal type of participatory practice (Ballie et al, 2000, drawing on Habermas); the other introduces theory to contribute to a more complex and conflictual understanding of participatory processes (Potvin, 2007, introducing Callon; Contradiopoulos, 2004, building on Bourdieu).

Habermas' theory of communicative action is introduced to suggest an ideal type of a collaborative process in which people share their different views and reach mutual understanding. While this approach provides health promoters with principles to facilitate and sustain such processes 
(e.g. Abelson et al, 2003) this is attained at the cost of complexity: By emphasizing "ideal speech situations" this approach primarily focuses on the micro-level of interactions between two types of actors (lay addressees vs. expert planners).

By contrast, the understanding of participatory processes in the actor-network perspective (Potvin, 2007) stresses the plurality of actors and their various and changing relations. This approach also considers the temporal character of participation as networks are never stable. Rather, actors, issues and relations develop recursively in stages. The heterogeneity of interests within a network and the questions of asymmetry and conflict between actors are further underlined by using Bourdieu's concept of "symbolic struggle" (Contandriopoulos, 2004). It points to the competition between perspectives and meanings that arise within and between different groups of lay people and the emergence of spokespersons. Analysing participation from a network perspective and as a symbolic struggle broadens the understanding towards general social processes that take place within participatory practices. However, by using social theory to stress "generality" the specificity of participation gets lost to a certain degree in both approaches.

\section{Conclusions}

We started with the assumption that the complex social phenomenon of participation in health promotion is approached quite differently by participatory methods, models and social theories and that the potential contribution of the latter has not been systematically highlighted so far. Therefore, a literature review was conducted on the use of social theories. Out of a large number of papers identified, in the end only a few turned out to make profound use of social theory. Using different social theories these papers analysed relevant aspects of participation in health promotion from different angles.

Our conclusions relate to three areas: future theoretical work, the specificity of social contexts in which participation is embedded and implications for models and participatory methods.

(1) The use of social theories in the literature reviewed certainly demonstrates the potentials of "generality" by tackling basic questions of participation. The quest for generality could gain from the application of social theories other than the ones identified as well as from a broader look at theoretical insights in fields other than health (e.g. science and technology). Yet, there seems to be an equal demand to further develop the "accuracy" of theoretical approaches for health promotion. More efforts could be made to link the debate on participation with theoretically informed debates in related areas of health promotion and health sociology. Two such areas are used as brief examples for the potential of "cross-fertilization".

In health promotion, the concept of "health literacy" has gained increased attention and has stimulated programme development and empirical research. Important conceptual work by Nutbeam (2000) reframed the concept of health literacy in a public health perspective. Pointing to different communicative arrangements to foster knowledge and action, Nutbeam differentiates three levels of health literacy: functional, directed towards understanding basic information about health risks and services; interactive, reflecting personal capacity for applying new information in changing circumstances; and critical, referring to personal and community capacity to act on social and economic determinants of health. There are obvious parallels related to communication theories identified in this review. Thus, research on health literacy could contribute to focusing specifically on the role of health-related knowledge within participatory health promotion. A second research area involves self-help groups, patient organizations and health movements (Kelleher, 2006; Brown and Zavestoski, 2004; Landzelius, 2006). Theoretical frameworks used for the analysis of these phenomena could be relevant by adding to questions of knowledge, identity and collective mobilization: The 
concept of "experiential expertise" refers to intersubjective construction, legitimation and deployment of a distinctive body of lay knowledge, as a basis for mutual aid as well as for epistemic claims vis á vis expert systems and for political mobilization. A further relevant area involves processes of incorporation of these organizations and movements as new "stakeholders" into the governance of health care and policy as well as medical research. Notions such as "scientization" or "colonization" critically discuss how incorporation reshapes the identity, knowledge and internal differentiation of organizations and movements.

(2) In the context of participation, future theoretical work could more appropriately consider that participation is a situational concept (Rifkin, 2009) applied in different practices, and fields and with different people. Theorizing participation therefore needs to demarcate the context which shapes its emergence. The theories identified mostly refer to the community level as the specific setting for participatory health promotion, but only two papers referred to its different meanings. As community is a contested term in social sciences (e.g. Jewkes and Murcott, 1996)., there is a need to consider more explicitly theoretical debates on community. A further challenge for theorizing participation in health promotion is analysing participation in organisational contexts more specifically. These are increasingly important settings for health promotion (e.g. workplace health promotion, healthy schools, health promoting hospitals) and their formal structures shape the meaning and implementation of participatory health promotion in quite specific ways.

(3) To identify implications of the social theoretical approaches reviewed for models and participatory methods, we start from the respective commonalities that social theories share with models (generality) and methods (accuracy). With respect to models, social theories could contribute to a more complex conceptualization of power. Power is usually visualized as a continuum which captures the outcomes rather than the processes of participation. Social theories point to multiple aspects of power and suggest that participation is more than determining outcomes of decisions. Decision processes are also shaped by the way they channel experiences and knowledge of different actors and develop options by establishing appropriate platforms of exchange. Models of participation could further develop their understanding of power by integrating the contribution and development of knowledge and by acknowledging the temporal dimension of participatory processes.

With respect to participatory methods, social theories note that these are not neutral devices but generate and shape lay knowledge and opinions in specific ways. Social status and its reproduction within communicative spaces play an important role. This not only holds for lay-expert interactions but also highlights struggles for social status between different lay actors. Social theories suggest complementing the simple expert/lay dichotomy and acknowledging the heterogeneity of and competition between lay actors. Altogether, this review showed that social theories thus far offer some key messages for the further development of appropriate models as well as for more reflected implementation of participation in practice. Additional theoretical underpinning is needed.

\section{References}

Abelson, J., Forest, P.-G., Eyles, J., Smith, P., Martin, E. and Gauvin, F.-P. (2003) Deliberations about deliberative methods: issues in the design and evaluation of public participation processes. Social Science and Medicine, 57(2): 239-251.

Arnstein, S.R. (1969) A ladder of citizen participation. Journal of the American Institute of Planners, 35(4): 216-224.

Baillie, L., Bassett-Smith, J. and Broughton, S. (2000) Using Communicative Action in the Primary Prevention of Cancer. Health Education and Behavior, 27(4): 442-453. 
Beck, U., Giddens, A. and Lash, S. (1994) Reflexive moderniszation. Politics, traditions and aesthetics in the modern social order. Stanford, CA: Stanford University Press.

Bourdieu, P. (1984) Distinction: a social critique of the judgement of taste. London: Routledge.

Brown, P. and Zavestoski, S. (2004) Social movements in health: an introduction. Sociology of Health and IIIness, 26(6): 679-694.

Bunton, R., Nettleton, S. and Burrows, R. (eds.) (1995) The Sociology of Health Promotion. Critical Analyses of Consumption, Lifestyle and Risk, London: Routledge.

Callon, M. (2001) Actor network theory. In: Smelster, N. and Balste, P. (eds.): International encyclopedia of the social and behavioral sciences, Oxford: Pergamon, 62-66.

Campbell, C. and Jovchelovitch, S. (2000) Health, Community and Development: Towards a Social Psychology of Participation. Journal of Community and Applied Social Psychology, 10: 255-270.

Contandriopoulos, D. (2004) A sociological perspective on public participation in public health. Social Science and Medicine, 58(2): 321-330.

Cornish, F. (2006) Empowerment to Participate: A Case Study of Participation by Indian Sex Workers in HIV Prevention. Journal of Community and Applied Social Psychology, 16: 301-315.

Cornwall, A. (ed.) (2011) The Participation Reader. London and New York: Zed Books.

Dutta, M.J. and Basnyat, I. (2008) The radio communication project in Nepal: A culture-centered approach to participation. Health Education and Behavior, 35(4): 442-454.

Freire, P. (1970) Pedagogy of the Oppressed. New York: Continuum.

Habermas, J. (1984) The Theory of Communicative Action, (vol. I) Reason and the Rationalisation of Society. Cambridge: Polity.

Hart, R.A. (1992) Children's Participation: From tokenism to citizenship. UNICEF ICDC: Florence.

Jewkes, R., Murcott, A. (1996) Meanings of Community. Social Science and Medicine 43(4): 555-563.

Kelleher, D. (2006) Self-help groups and their relationship to medicine. In: D. Kelleher, J. Gabe and G.H. Williams (eds.) Challening Medicine, London: Routledge, pp. 104-121.

Labonte, R. (1997) Power, Participation and Partnership for Health Promotion. Victorian Health Promotion Foundation: Victoria.

Landzelius, K. (2006) Introduction: Patient organization movements and new metamorphoses in patienthood. Social Sciemce and Medicine, 62(3): 529-537.

Morgan, L.M. (2001) Community participation in health: perpetual allure, persistent challenge. Health Policy and Planning, 16, (3): 221-230.

Morris, N. (2003) A comparative analysis of the diffusion and participatory models in development communication. Communication Theory, 13(2): 225-248.

Murphy, N.J. (2005) Citizen deliberation in setting health-care priorities. Health Expectations, 8(2): 172-181.

Noblit, G.W. and Hare, R.D. (1988) Meta-ethnography: synthesising qualitative studies. London: Sage. Nutbeam, D. (2000) Health literacy as a public health goal: a challenge for contemporary health education and communication strategies into the 21st century. Health Promotion International, 15(3): 259-267.

Paterson, B.L., Thorne, S.E., Canam, C. and Jillings, C.R. (2001) Meta-Study of Qualitative Health Research: A Practical Guide to Meta-Analysis and Meta-Synthesis. Thousand Oaks, CA: Sage Publications.

Petersen, A. and Lupton, D. (1997) The New Public Health. Health and self in the age of risk. London: Sage Publications.

Potvin, L. (2007) Managing Uncertainty through Participation, In: McQueen, D.V. and. Kickbusch, I.S. (eds.) Health and Modernity: The Role of Theory in Health Promotion, New York: Springer, 103-128. Preston, R., Waugh, H., Larkins, S., and Taylor, J. (2010) Community participation in rural primary health care: intervention or approach? Australian Journal of Primary Health 16: 4-16. 
Ramella, M. and de la Cruz, R.B. (2000) Taking Part in Adolescent Sexual Health Promotion in Peru: Community Participation from a Socal Psychological Perspective. Journal of Community and Applied Social Psychology, 10: 271-284.

Rifkin, S.B., Lewando-Hundt, G. and Draper, A.K. (2000) Participatory approaches in health promotion and health planning. A literature review, London: Health Development Agency.

Rifkin, S.B. and Pridmore, P. (2001) Partners in Planning - Information, participation and empowerment, Oxford: Macmillan.

Rifkin, S.B. (2009) Lessons from community participation in health programmes: a review of the post Alma-Ata experience. International Health 1(1):31-36.

Rootman, I., Goodstadt, M., Potvin, L., and Springett, J. (2001) A framework for health promotion evaluation, In: Rootman, I. Goodstadt, M., Hyndman, B., McQueen, D.V., Potvin, L., Springett, J., Ziglio, E. (eds.) Evaluation in health promotion: principles and perspectives. Copenhagen: WHO, 7-38.

Stephens, C. (2007) Participation in Different Fields of Practice: Using Social Theory to Understand Participation in Community Health Promotion. Journal of Health Psychology, 12(6): 949-960.

Taylor, C. (1985) Human Agency and Language. New York: Cambridge University Press.

Tritter, J.Q. and McCallum, A. (2006) The snakes and ladders of user involvement: Moving beyond Arnstein. Health Policy, 76(2): 156-168.

Wait, S. and Nolte, E. (2006) Public involvement policies in health: exploring their conceptual basis. Health Economics, Policy and Law, 1(2): 149-162.

Wallerstein, N. (1992) Powerlessness, Empowerment, and Health: Implications for Health Promotion Programs. American Journal of Health Promotion, 6, (3): 197-205.

Weick, K. (1979) The social psychology of organizing. Reading, MA: Addison-Wesley.

White, D. (2000) Consumer and Community Participation: A Reassessment of Process, Impact and Value. In: Albrecht, G.L., Fitzpatrick, R. and Scrimshaw, S.C. (eds.) Handbook of Social Studies in Health and Medicine. London: Sage Publications, 465-480.

WHO (1978) Alma Ata Declaration. Copenhagen: WHO.

WHO (1986) Ottawa charter for health promotion. Geneva: WHO.

Zakus, J.D.L. and Lysack, C.L. (1998) Revisiting community participation. Health Policy and Planning, 13(1): 1-12. 